\title{
Association between the expression of carbonic anhydrase II and clinicopathological features of hepatocellular carcinoma
}

\author{
HUI ZHANG ${ }^{1 *}$, CHANGHUA ZHUO $^{2 *}$, DONG ZHOU ${ }^{1}$, FAN ZHANG $^{1}$, MINYONG CHEN $^{1}$, \\ SHAOHUA XU ${ }^{1}$ and ZHAOSHUO CHEN ${ }^{1}$
}

Departments of ${ }^{1}$ Hepatobiliary and Pancreatic Surgical Oncology, and ${ }^{2}$ Gastrointestinal Surgical Oncology, Fujian Provincial Cancer Hospital and Fujian Medical University Cancer Hospital, Fuzhou, Fujian 350014, P.R. China

Received September 19, 2017; Accepted June 7, 2018

DOI: $10.3892 / \mathrm{ol} .2019 .10242$

\begin{abstract}
The present study aimed to examine the molecular marker associated with the therapy and prognosis of hepatocellular carcinoma (HCC), and further investigate the association between its expression and the clinicopathological features of HCC. To select the core genes closely associated with HCC, differentially expressed genes (DEGs) were analyzed and screened from Gene Expression Omnibus datasets (GSE 36376) using a bioinformatics approach. Tumor and adjacent tissues were collected form 112 patients of HCC who were treated by radical resection. The expression levels of carbonic anhydrase II (CA2) in the tumor and adjacent tissues were determined using reverse transcription-quantitative polymerase chain reaction analysis and immunohistochemistry. The $\chi^{2}$ test was applied for observing the association between the expression of CA2 and clinicopathological features of patients with HCC. The effects of the expression of CA2 on the patients' overall survival (OS) and disease-free survival (DFS) were examined via Kaplan-Meier analysis. A total of 83 DEGs were screened and analyzed using gene network analysis, among which $\mathrm{CA} 2$ had direct interactions with more than one disease gene of HCC. The results of immunohistochemistry showed that CA2 was expressed at a lower level in the tumor tissues compared with the adjacent tissues $(t=3.012, P=0.010)$. Single factor analysis revealed that the mRNA expression of CA 2 was able to predict the recurrence of HCC, and was significantly associated with $\alpha$-fetoprotein
\end{abstract}

Correspondence to: Dr Dong Zhou, Department of Hepatobiliary and Pancreatic Surgical Oncology, Fujian Provincial Cancer Hospital and Fujian Medical University Cancer Hospital, 420 Fuma Street, Jinan, Fuzhou, Fujian 350014, P.R. China

E-mail: zhoudong_0801@163.com

*Contributed equally

Key words: hepatocellular carcinoma, carbonic anhydrase II, clinicopathological features, differentially expressed genes
(AFP), microvascular invasion, tumor-node-metastasis (TNM) staging, and recurrence $(\mathrm{P}<0.05)$. The expression levels of AFP, CA2 and TNM staging were confirmed to be independent prognostic factors of HCC $(\mathrm{P}<0.05)$. Kaplan-Meier analysis demonstrated that the group with a high expression of CA2 showed increased DFS and OS, compared with the low expression group $(\mathrm{P}<0.05)$. These findings indicated that elevated CA2 increased DFS and OS of HCC, which suggested that CA2 may be a potential target for HCC therapy.

\section{Introduction}

Hepatocellular carcinoma (HCC) is one of the most common types of malignant tumor (1-5), with a mortality rate of $>1,000,000$ every year worldwide. HCC remains a global health problem with increasing morbidity rates and considerable mortality rates, having serious effects on human health. Although surgery is an effective therapy for HCC currently (6-8), there are malpractices in several aspects, including anesthesia, surgical risk and postoperative complications, and the majority of patients with HCC of occult onset have missed the optimal timing for surgical treatment. Therefore, biomarkers of HCC are an important and unmet requirement for the diagnosis, treatment and prognosis of HCC.

Gene chip technology provides a novel approach for the identification of biomarkers, and its high throughput has facilitated investigations of gene expression, disease diagnosis and treatment, targeted drugs and curative effects. In addition, using bioinformatics methods to analyze gene chip data can maximize the retrieval of hidden information in large quantities of data. In previous years, HCC and healthy control groups have been analyzed and compared through protein-protein interaction (PPI) analysis, which has identified markers of disease occurrence and development, providing a theoretical basis for the development of targeted drugs (9). Carbonic anhydrases (CAs), a crucial family of 16 isoenzymes, distribute in different tissues (10). Carbonic anhydrase II (CA2), first identified in red blood cells as monomers, have been suggested to be a prognostic factor of several tumor diseases, including pancreatic (11), colorectal (12) and gastric cancer (13), and 
peritoneal myxoma (14). At present, the major biomarkers of HCC are ETS2 (15), Rac GTPase-activating protein 1 (16), matrix metalloproteinase, 3-phosphoinositide-dependent protein kinase-1 (PDK1) and FOS. The expression of PDK1 was found to be high in HCC cells following radical surgery, which was associated with the patient prognosis (17), however, the association between the expression of CA2 and HCC remains to be elucidated.

Through observing the change in the expression of CA2 in $\mathrm{HCC}$, and assessing the clinical features and prognosis of patients, the present study investigated the association between the expression of CA2 and clinicopathological features of $\mathrm{HCC}$, in order to provide an experimental and theoretical basis for the improvement of HCC treatment.

\section{Materials and methods}

Search and download of HCC gene expression data. Two gene expression data sets of HCC following radical surgery: GSE36376 and GSE22058, were obtained by searching 'Hepatocellular Carcinoma' and 'Curative Hepatectomy' in the Gene Expression Omnibus (GEO) datasets (http://www. ncbi.nlm.nih.gov/geo/). GSE22058 has three chip platforms: GPL6793, GPL9733 and GPL10457, with 397 samples in total. The GSE36376 dataset selected by Lim et al uses the chip platform GPL10558, with 433 samples in total. According to the standard of the 7th American Joint Committee on Cancer (AJCC) (18), the severity degrees of HCC can be ranked as I-III stages. The samples (193 tumor tissues and 240 adjacent tissues were sorted according to the Title, and the data of the tumor and adjacent tissues of the same patient were matched and downloaded.

Analysis of gene chip data and differentially expressed genes (DEGs). Gene chip data analysis in GEO was performed in R-software 3.4.0. software with its normalization perfected and innovated by Limma (http://www.bioconductor.org/packages/release/bioc/html/limma.html). The DEGs of different stages in the tumor and adjacent tissues were detected using a paired t-test. Multiple verification was executed using the NormalizeBetweenArrays method. The genes with adj $\mathrm{P}<0.01$ and an absolute value of $\log \mathrm{FC}>1.8$ were regarded as the DEGs.

HCC-associated genes and meta-analysis. The genes associated with HCC were searched in DigSee (http://210.107.182.61/digseeOld/) with 'Hepatocellular Carcinoma' as the key word (TP53, AFP, ADAM17, VEGFA, PTGS2, CTNNB1, CCND1, BCL2L1, AEN, TNF, MAPK1, IFNA5). Using the analysis tool of the Search Tool for the Retrieval of Interacting Genes (STRING; https://string-db. org/cgi/input.pl) database, the associations of these genes associated with the DEGs were identified. The molecular function, signaling pathways and biological ways of $\mathrm{HCC}$, and the interaction of these DEGs were examined by functional enrichment analysis.

Patient and sample collection. A total of 112 patients undergoing radical surgery were selected from Fujian Provincial Cancer Hospital (Fujian, China) between January 2012 and January 2013. The inclusive criteria were as follows: Patients with pathological diagnosis confirmed; no radiotherapy and chemotherapy prior to surgery; no distant metastasis; provision of signed informed consent. The exclusion criteria were as follows: Patients with incomplete clinical data; presence of systemic disease; presence of other malignant tumors; pregnant or lactating. The tumor and adjacent tissue samples were collected from the patients with HCC. The degrees of severity of HCC were ranked as I-III stages in accordance with the standard of the 7th AJCC. Following the patient being admitted to hospital, $5 \mathrm{ml}$ peripheral blood was collected into vascular tubes, and within $2 \mathrm{~h}$ serum was extracted at room temperature for $40 \mathrm{~min}$, centrifuged for $1,000 \mathrm{x} \mathrm{g}$ for $10 \mathrm{~min}$ and preserved at $-80^{\circ} \mathrm{C}$.

Follow-up survey. All 112 patients were followed-up by telephone and clinic visits 3, 6, 9, 12, 18 and 24 months following radical surgery, and during visits once each year from month 36 following radical surgery. The overall survival (OS) and disease-free survival (DFS) of the patients were observed until December 2016 with a median follow-up time of 34 months. The OS was determined as the time from randomization to mortality due to any cause. The DFS was defined as the time from randomization to the recurrence of primary disease or mortality.

Extraction of total RNA. The total RNA of the 122 patients' tumor and adjacent tissue samples were extracted using TRIzol (Beijing Biotechnology Co., Ltd., Beijing, China), according to the manufacturer's protocol. The tissue samples were added to $500 \mu \mathrm{l}$ TRIzol and $200 \mu \mathrm{l}$ trichloromethane, shaken and rested, and then placed in a centrifuge (Hunan Kaida Laboratory Co., Ltd., Hunan, China) at $12,000 \mathrm{x}$ g for $10 \mathrm{~min}$ at $4^{\circ} \mathrm{C}$, followed by the addition of isopropanol and ethanol, centrifugation, and discarding the supernatant. The RNA was dissolved with 20-50 $\mu \mathrm{l}$ diethylpyrocarbonate (DEPC)- $\mathrm{ddH}_{2} \mathrm{O}$, dehydrated with ethanol and preserved in a refrigerator at $-70^{\circ} \mathrm{C}$.

Reverse transcription-quantitative polymerase chain reaction $(R T-q P C R)$ analysis. The RNA was extracted by TRIzol (Beyotime Institute of Biotechnology, Beijing, China). The RT-qPCR analysis was performed according to the protocol of the reverse transcription and amplification kit (Roche Diagnostics, Basel, Switzerland) (2X SYBR-Green qPCR Mix; $10 \mu 1$; Forward primer $(10 \mu \mathrm{mol} / \mathrm{l}), 1 \mu \mathrm{l}$; reverse primer $(10 \mu \mathrm{mol} / \mathrm{l})$, $1 \mu \mathrm{l}$; cDNA, $1 \mu \mathrm{l}$; DEPC-dd $\mathrm{H}_{2} \mathrm{O}, 7.0 \mu \mathrm{l}$ ). The reaction conditions were as follows: 40 cycles of 5 min of pre-denaturation at $95^{\circ} \mathrm{C}$, $5 \mathrm{sec}$ of denaturation at $95^{\circ} \mathrm{C}$, and $30 \mathrm{sec}$ of annealing at $60^{\circ} \mathrm{C}$, replacing the cDNA template with DEPC- $\mathrm{ddH}_{2} \mathrm{O}$ as a negative control. The primer sequence were as follows: CA2, forward 5'-AAACAAAGGGCAAGAGTGCT-3' and reverse 5'-GAG CACAATCCAGGTCACAC-3'; glyceraldehyde-3-phosphate dehydrogenase (GAPDH), forward 5'-CATGAGAAGTATGAC AACAGCCT-3' and reverse 5'-AGTCCTFCCACGATACCA AAGT-3'. The primers were synthesized by Shanghai Biological Engineering Co., Ltd. (Shanghai, China). And the data was analysed by $2^{-\Delta \Delta \mathrm{Cq}}$ method (19).

Immunohistochemistry. The tumor and adjacent tissue samples were paraffin-embedded and cut into 5- $\mu \mathrm{m}$ sections. Following dewaxing with dimethylbenzene and hydration, the sections were added to citrate, boiled, rinsed three 
times ( 3 min each rinse) with PBS, blocked for 15 min with $5 \%$ fetal bovine serum (Gibco; Thermo Fisher Scientific, Inc.) and incubated with CA2 antibody (dilution, 1:1,000; cat. no. ab191343) overnight in a wet box at $4^{\circ} \mathrm{C}$. The tissue sections were then rinsed three times ( $3 \mathrm{~min}$ each rinse). The tissues were added to diaminobenzidine solution (Shanghai Fu Sheng Industrial Co., Ltd., Shanghai, China) for $10 \mathrm{~min}$ at room temperature, stained by hematoxylin, differentiated for $5 \mathrm{sec}$ with $\mathrm{HCI}+$ ethanol, washed for $20 \mathrm{~min}$, hydrated with an ethanol concentration gradient, and mounted. The median integral optical density (mIOD) was used as the cut-off point. All samples were divided into a high CA2 expression group (IOD $>$ mIOD) and low CA2 expression group (IOD $<$ mIOD).

Statistical analysis. R 3.4.0 software (https://cran.r-project. org/bin/windows/base/) was used for analyzing data. Quantitative data are presented as the mean \pm standard deviation. A Kolmogorov-Smirnov test was applied to assess the normal distribution of data. If in a normal distribution, the mean of the measurement data among groups were compared using a Student t-test; if not, data were compared using a Mann-Whitney $U$ test. The enumeration data are expressed as case number and percentage, and were examined using a $\chi^{2}$ test. The expression of CA2, and patients OS and DFS were analyzed using Kaplan-Meier analysis. The patients survival rates were compared using a log-rank test. COX regression analysis was used to evaluate the prognostic value of CA2 and other parameters in HCC. $\mathrm{P}<0.05$ was considered to indicate a statistically significant difference.

\section{Results}

DEGs in patients with and without relapse. There were 21,594 expressed genes (9,363 genes in stage I, 7,876 genes in stage II, and 4,355 genes in stage III) obtained through GEO analysis. Subsequently, the genes with an absolute value of $\log$ FC $>1.8$ were selected and analyzed further. In total, 83 genes were differentially expressed in the three stages (Fig. 1).

Interaction network of the DEGs. According to the STRING database, there were 83 genes, which were differentially expressed in the three stages, among which 44 genes interacted with associated genes of HCC (Fig. 2) and the majority of these have been investigated in HCC. CA2 was expressed at a low level in HCC. However, there has been no report on the mechanism of CA2 in $\mathrm{HCC}$ or its association with the clinicopathological features of HCC.

Expression of CA2 in the tumor and adjacent tissues. The expression levels of CA2 in the tumor and adjacent tissues were observed via immunohistochemistry, which showed that the expression of CA2 in the tumor tissues was lower, compared with that in the adjacent tissues (Fig. 3). The patients were then divided into CA 2 high and low expression groups to examine the association between the expression of CA2 and the clinicopathological features of HCC.

Greyscale maps of CA2 in the tumor and adjacent tissues. The grey ratios of $\mathrm{CA} 2$ in the tumor and adjacent tissues and their mean values were assessed. The grey ratio of CA2 in

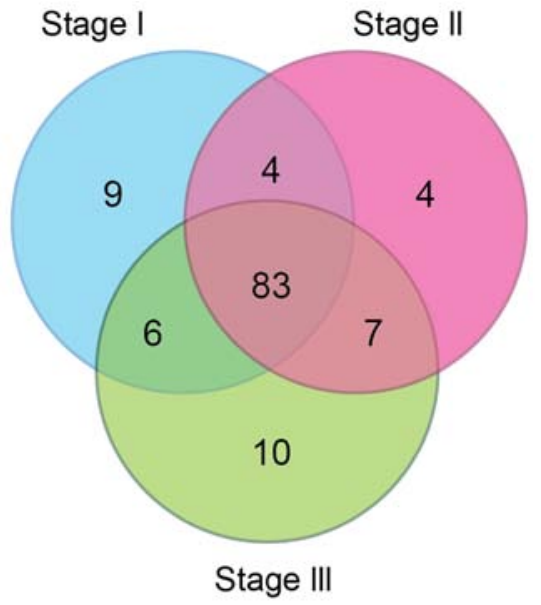

Figure 1. DEGs in tumor-node-metastasis stage. DEGs were integrated using online software (http://bioinformatics.psb.ugent.be/webtools/Venn/). The Venn diagram shows that there were 83 DEGs in the three stages of hepatocellular carcinoma. DEGs, differentially expressed genes.

the adjacent tissues was $(0.75 \pm 0.15)$, and in the tumor tissues was $(0.57 \pm 0.12)$, which was a statistically significant difference $(\mathrm{t}=9.918, \mathrm{P}<0.001$; Fig. $4 \mathrm{~A})$. On comparing the expression of CA2 in the tumor and adjacent tissues, the expression of CA2 in the 112 tumor tissues was lower, compared with that in the adjacent tissues $(\mathrm{t}=3.012, \mathrm{P}=0.010$; Fig. 4B).

Association between the expression of CA2 and clinicopathological features of HCC. There was a significant difference in $\alpha$-fetoprotein (AFP), microvessel infiltration, tumor-node-metastasis (TNM) staging and recurrence under different expression levels of CA2 $(\mathrm{P}<0.05)$. There was no significant difference in age, sex, $\mathrm{HBsAg}$, Child-Pugh score, chronic interstitial hepatitis, tumor diameter or tumor number between the two groups ( $\mathrm{P}>0.05$; Table I).

Association between the expression of CA2 and HCC prognosis. In the present study, 66 of the 112 patients suffered from relapse during the follow-up period. Of these, there were 54 cases of patients with intrahepatic metastasis, four with pulmonary metastasis, and eight with pulmonary and intrahepatic metastasis. Single factor analysis showed that the AFP level, TNM staging, microvascular invasion, and expression of CA2 may be risk factors in determining prognosis. Combined with the single factor analysis, the multivariate COX regression analysis showed that the AFP level $(\mathrm{HR}=1.378 ; 95 \% \mathrm{CI}=0.209-0.897, \mathrm{P}<0.05)$, expression of CA2 $(\mathrm{HR}=0.433 ; 95 \% \mathrm{CI}=2.402-20.979, \mathrm{P}<0.05)$, and TNM staging $(\mathrm{HR}=7.098 ; 95 \% \mathrm{CI}=1.105-1.717, \mathrm{P}<0.05)$ were independent prognostic factors for HCC (Table II). Kaplan-Meier analysis showed the high CA2 expression group presented with higher DFS $(\mathrm{P}<0.05)$ and OS $(\mathrm{P}<0.05)$, compared with the low expression group (Fig. 5A and B), which indicated that $\mathrm{CA} 2$ may be a potential target for the prognosis of $\mathrm{HCC}$.

\section{Discussion}

HCC is the main cause of cancer-associated mortality $(8,20)$. It is not easy to make an early diagnosis as there are no obvious 
Table I. Association between the expression of CA2 and clinicopathologic features of hepatocellular carcinoma.

\begin{tabular}{|c|c|c|c|c|}
\hline \multirow[b]{2}{*}{ Variable } & \multicolumn{2}{|c|}{ Expression of CA2, n (\%) } & \multirow[b]{2}{*}{$\chi^{2}$} & \multirow[b]{2}{*}{ P-value } \\
\hline & Low $(\mathrm{n}=59)$ & $\operatorname{High}(\mathrm{n}=53)$ & & \\
\hline \multicolumn{5}{|l|}{ Age (years) } \\
\hline$<50$ & $41(69.49)$ & $37(69.81)$ & \multirow[t]{2}{*}{0.001} & \multirow[t]{2}{*}{0.971} \\
\hline$\geq 50$ & $18(30.51)$ & $16(30.19)$ & & \\
\hline \multicolumn{5}{|l|}{ Sex } \\
\hline Male & $42(71.19)$ & $39(73.58)$ & \multirow[t]{2}{*}{0.08} & \multirow[t]{2}{*}{0.777} \\
\hline Female & $17(28.81)$ & $14(26.42)$ & & \\
\hline \multicolumn{5}{|l|}{ HbsAg } \\
\hline Positive & $10(16.95)$ & $9(16.98)$ & \multirow[t]{2}{*}{$<0.01$} & \multirow[t]{2}{*}{0.996} \\
\hline Negative & $49(83.05)$ & $44(83.02)$ & & \\
\hline \multicolumn{5}{|c|}{ Child-Pugh score } \\
\hline $\mathrm{A}$ & $55(93.22)$ & $50(94.34)$ & \multirow[t]{2}{*}{0.06} & \multirow[t]{2}{*}{0.807} \\
\hline B & $4(6.78)$ & $3(5.66)$ & & \\
\hline \multicolumn{5}{|c|}{ Liver cirrhosis } \\
\hline Yes & $50(84.75)$ & $46(86.79)$ & \multirow[t]{2}{*}{0.096} & \multirow[t]{2}{*}{0.757} \\
\hline No & $9(15.25)$ & $7(13.21)$ & & \\
\hline \multicolumn{5}{|c|}{$\mathrm{AFP}(\mathrm{ng} / \mathrm{ml})$} \\
\hline$<100$ & $19(32.20)$ & $29(54.72)$ & \multirow[t]{5}{*}{14.48} & \multirow[t]{5}{*}{0.006} \\
\hline $100-400$ & $7(11.86)$ & $11(20.75)$ & & \\
\hline $400-800$ & $4(6.78)$ & $4(6.78)$ & & \\
\hline $800-1,210$ & $4(6.7842 .37)$ & $3(5.66)$ & & \\
\hline$\geq 1,210$ & $25(42.37)$ & $6(11.32)$ & & \\
\hline \multicolumn{5}{|c|}{ Tumor diameter $(\mathrm{cm})$} \\
\hline$\leq 5$ & $41(69.49)$ & $37(69.81)$ & \multirow[t]{2}{*}{0.001} & \multirow[t]{2}{*}{0.971} \\
\hline$>5$ & $18(30.51)$ & $16(30.19)$ & & \\
\hline \multicolumn{5}{|c|}{ Tumor number } \\
\hline Single & $12(20.34)$ & $12(22.64)$ & \multirow[t]{2}{*}{0.088} & \multirow[t]{2}{*}{0.767} \\
\hline Multiple & $47(79.66)$ & $41(77.36)$ & & \\
\hline TNM stage & & & & \\
\hline I-II & $11(18.64)$ & $28(52.83)$ & 14.377 & $<0.001$ \\
\hline III-IV & $48(81.36)$ & $25(47.17)$ & & \\
\hline Microvascu & & & & \\
\hline Yes & $34(57.63)$ & $16(30.19)$ & 8.506 & 0.004 \\
\hline No & $25(42.37)$ & $37(69.81)$ & & \\
\hline Recurrence & & & & \\
\hline Yes & $48(81.36)$ & $18(33.96)$ & 25.911 & $<0.001$ \\
\hline No & $11(18.64)$ & $35(66.04)$ & & \\
\hline
\end{tabular}

AFP, $\alpha$-fetoprotein; TNM, tumor-node-metastasis; CA2, carbonic anhydrase II.

Table II. Multivariate COX regression analysis of factors associated with recurrence.

\begin{tabular}{lccrrrr}
\hline Variable & B & SE & Wald & P-value & Exp (B) & $95 \%$ CI \\
\hline AFP $(>400$, vs. $\leq 400 \mathrm{ng} / \mathrm{ml})$ & 0.320 & 0.112 & 8.128 & 0.004 & 1.378 & $0.209-0.897$ \\
TNM stage (I/II, vs. III/IV) (30) & 1.960 & 0.553 & 12.566 & $<0.001$ & 7.098 & $1.105-1.717$ \\
CA2 expression (low and high) & -0.836 & 0.371 & 5.079 & 0.024 & 0.433 & $2.402-20.979$ \\
\hline
\end{tabular}

AFP, $\alpha$-fetoprotein; TNM, tumor-node-metastasis; CA2, carbonic anhydrase II. 


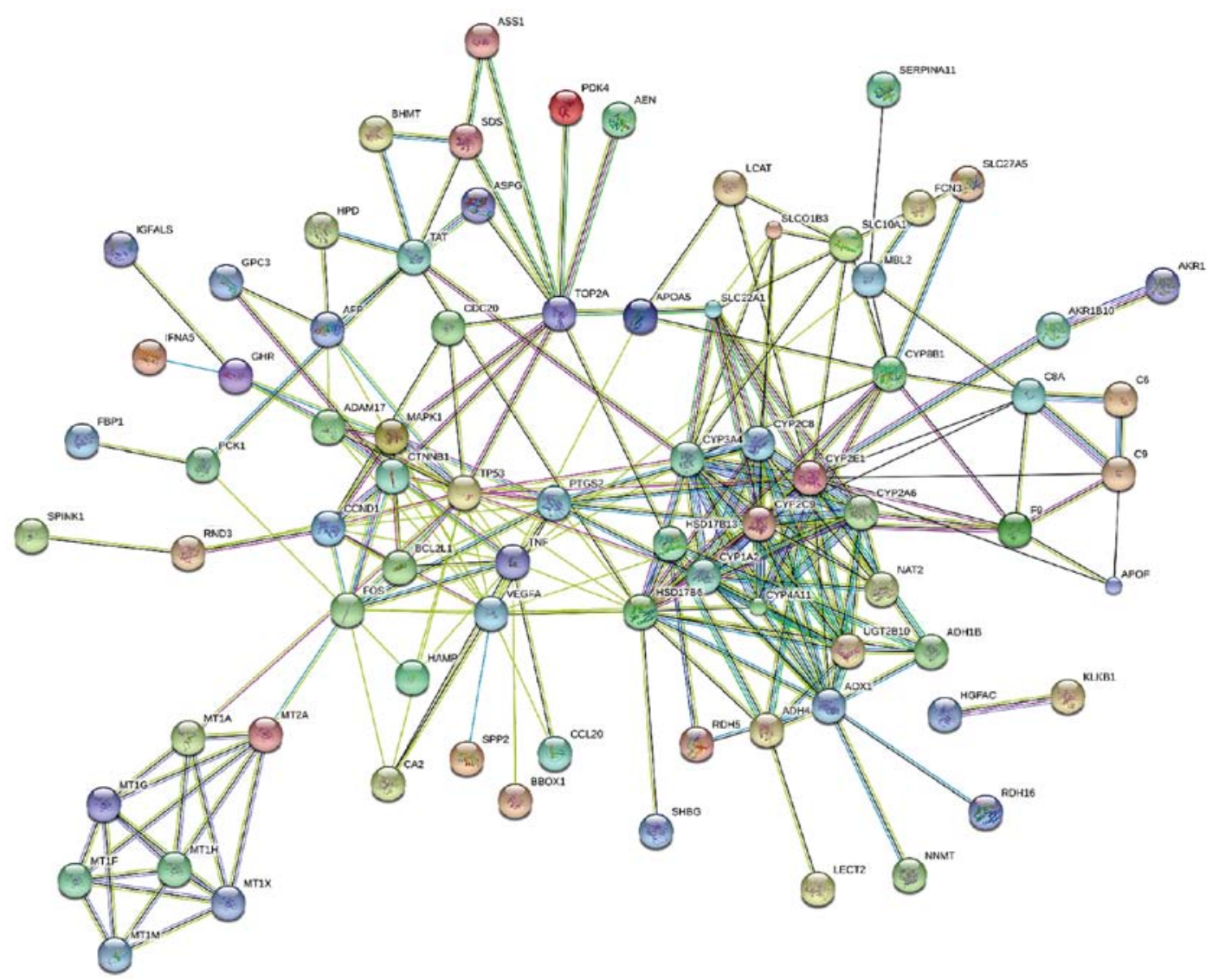

Figure 2. Network map of HCC genes. The protein-protein interaction data of HCC was obtained from the Search Tool for the Retrieval of Interacting Genes database, which indicated that carbonic anhydrase II was involved in the occurrence and development of HCC. Line: The protein-protein interaction. The thicker the line, the stronger the effect. Spheres: HCC genes. HCC, hepatocellular carcinoma.
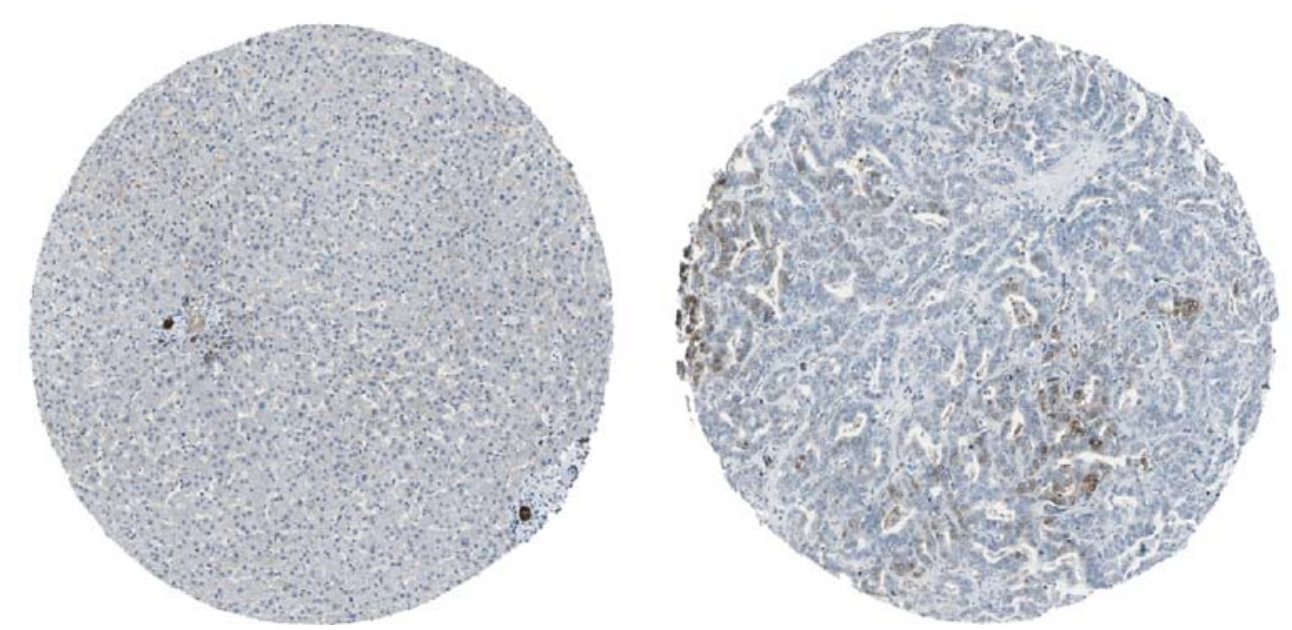

Figure 3. Expression of CA2 in serum samples. The expression of CA2 in serum samples of 112 patients with hepatocellular carcinoma was detected using immunohistochemistry (magnification, x200). Normal liver tissues showed a high level of expression whereas tumor tissues showed low expression. CA2, carbonic anhydrase II.

symptoms in the early stage. Therefore, the majority of patients lose the chance to undergo radical surgery, which seriously threatens patient health and quality of life (21). The prognosis of patients is poor (22). The traits of complex diseases are affected by the interaction of multiple genes. Gene analysis based on interaction between genes can effectively produce biological information, providing valid scientific reference for the diagnosis, treatment and improvement of prognosis. Following the rapid development of genomic science, a large quantity of genomic data and gene expression data have provided a novel basis for the investigation of gene-gene and gene-environment interactions (23-25). By analyzing the existing data through systems biology approaches, it is possible to investigate the association between gene function, protein interaction and the occurrence of diseases, and construct a detailed network of the occurrence and progression of diseases. Previously, 
A

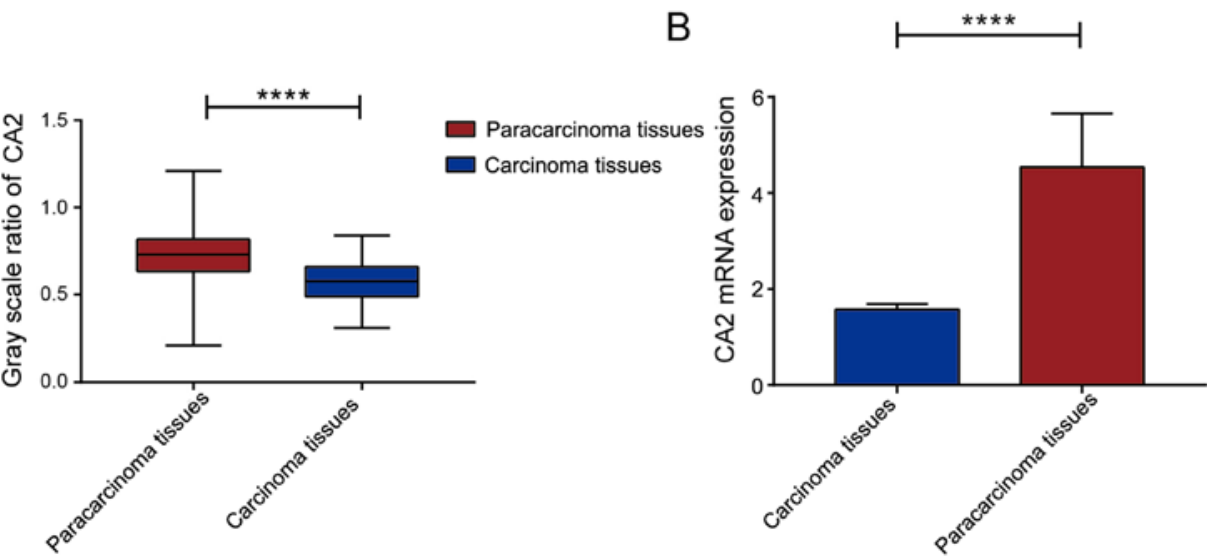

Figure 4. Expression of CA2. (A) Western blot analysis demonstrated that, in $112 \mathrm{HCC}$ cases, the expression of CA2 was lower, compared with that in paired adjacent paracarcinoma tissues. (B) Expression of CA2 in tumor and adjacent tissues from 112 patients with HCC was determined using reverse transcription-quantitative polymerase chain reaction analysis and analyzed using a paired $\mathrm{t}$-test. ${ }^{* * * *} \mathrm{P}<0.0001$ vs. carcinoma. Blue, tumor tissues; red, adjacent tissues. HCC, hepatocellular carcinoma; CA2, carbonic anhydrase II.

A

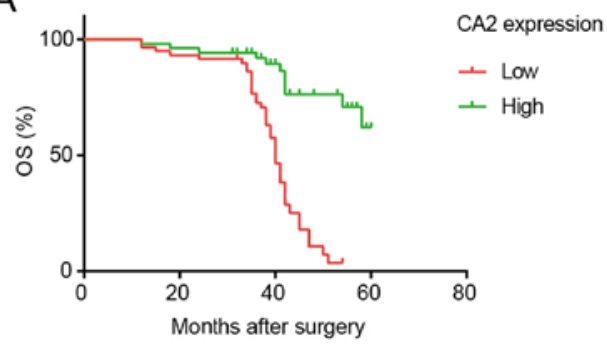

B

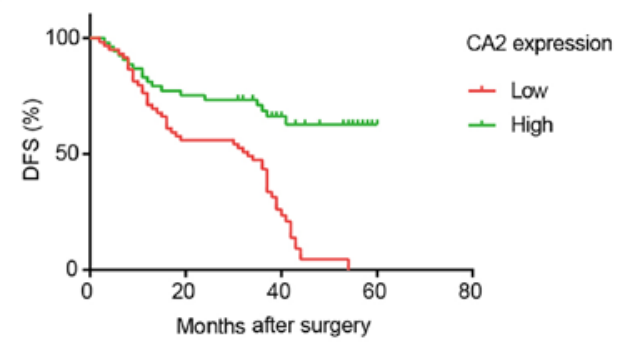

Figure 5. Association between CA2 and hepatocellular carcinoma patient survival rate. The association between the expression of CA2 and patient prognosis was assessed using Kaplan-Meier survival curves. Green, high expression of CA2; red, low expression of CA2. OS, overall survival; DFS, disease-free survival; CA2, carbonic anhydrase II.

the molecular mechanism of hepatitis $\mathrm{C}$ virus (HCV) protein in the progression of $\mathrm{HCC}$ was investigated by topological analysis of a PPI network (26). Through constructing the PPI network of DEGs in chronic HCV and HCC samples, interaction among DEGs and key microRNAs were confirmed using the STRING and GeneMANIA databases, which provided a foundation for subsequent investigations of mechanisms and clinical application. In the present study, it was found that 83 genes were differentially expressed in the three stages of HCC, based on the GEO of HCC. The gene network map of HCC was constructed according to the PPI data obtained using the STRING method, in which the majority of genes were found to be associated with the HCC genes. Among the DEGs, CA2 had a direct interaction with several HCC genes, but has received limited investigation. Therefore, the present study focused on the role of CA2 in HCC.

CAs have a variety of functions, including carbon dioxide $\left(\mathrm{CO}_{2}\right)$ transport, $\mathrm{pH}$ adjustment, ion transport, gastric acid formation, bone resorption, calcification and genesis, development, and tumor invasion $(27,28)$. As one isoenzyme of CA, CA2 is widely distributed in vivo and has the highest activity. The main function of CA2 is to catalyze the hydration of $\mathrm{CO}_{2}$, which can readily pass through the cell membrane. Therefore, $\mathrm{CA} 2$ being widely present in the cytoplasm can regulate $\mathrm{HCO}_{3}$ balance by promoting $\mathrm{CO}_{2}$ transmembrane transport. It has been suggested that the $\mathrm{pH}$ of cancer tissues is lower than that of adjacent normal tissues, possibly due to $\mathrm{CA} 2$ being involved in the acidification process of the extracellular microenvironment by the reversible catalysis of $\mathrm{CO}_{2}$ and $\mathrm{HCO}_{3}$ - The acidification of the microenvironment is beneficial to tumor invasion, which suggests that CA2 is an indicator of poor clinical prognosis. Therefore, differences in the expression of CA2 has a significant effect on the occurrence, progression and biological behavior of cancer. Previous studies have shown that CA2 was either absent or was expressed at low levels in the majority of tumors (12). In a study by $\mathrm{Hu}$ et al (13) CA2 in tumor and adjacent tissues were separately collected from patients with gastric cancer, and its content was analyzed following radical surgery via immunohistochemistry. The results showed that the content of CA2 in tumor tissues was significantly lower than that in normal gastric mucosa tissues, and that the downregulation of CA2 was correlated with tumor size and stage, and a low survival rate. AFP is a type of glycoprotein synthesized by endoplasmic reticulum in hepatocytes and is also a tumor marker of HCC, which is valuable for tumor prognosis. AFP content and the survival curve of patients with $\mathrm{HCC}$ were measured respectively using an electrochemiluminescence immunoassay and Kaplan-Meier analysis, which showed that the survival rate of patients with an AFP $>400 \mu \mathrm{g} / 1$ was reduced, compared with that of patients with an AFP $<400 \mu \mathrm{g} / 1$ (29). In the present study, Spearman's correlation analysis showed that CA2 was negatively correlated 
with AFP content. The expression of CA2 in the HCC tissues was decreased and correlated with AFP, microvascular invasion, differentiation degree and tumor stage. Kaplan-Meier analysis suggested that patients with a low expression of CA2 had a poor prognosis, and COX regression analysis showed that the expression of CA2 was an independent prognostic factor for HCC, which was consistent with the study by $\mathrm{Hu}$ et al (13). Therefore, it was hypothesized that CA2 may be involved in the occurrence and progression of $\mathrm{HCC}$, was correlated with the prognosis of patients, and may be used as an independent prognostic factor in patients with HCC.

The present study demonstrated firstly that CA2 was crucial in determining the clinical characteristics and prognosis of HCC by combining expression profiling and clinical data of cases of HCC. The results showed that the downregulation of CA2 in HCC was significantly correlated with the clinical characteristics and prognosis of HCC. These findings demonstrated the role of CA2 in the occurrence and progression of $\mathrm{HCC}$, which is significant for predicting the postoperative survival rate of patients.

In conclusion, the present study examined the expression of CA 2 in tumor and adjacent tissues using bioinformatics analysis, and analyzed the value of the expression of CA2 in the progression and prognosis of $\mathrm{HCC}$. The findings suggested that the involvement of $\mathrm{CA} 2$ is pivotal in $\mathrm{HCC}$, and is expected to be an independent prognostic factor and a potential target for the treatment of HCC.

\section{Acknowledgements}

Not applicable.

\section{Funding}

This study was supported by the Special Fiscal Funds of Fuji an Province (grant no. 2016-490) and the Natural Science Funds of Fujian province (grant no. 2018J01269).

\section{Availability of data and materials}

All data generated or analyzed during this study are included in this published article.

\section{Authors' contributions}

$\mathrm{HZ}$ designed the present study. CZ wrote the manuscript, contributed to the design of the present study and conducted the experiments. DZ, FZ, MC, SX and ZC assisted in the analysis and interpretation of the results. All authors read and approved the final manuscript.

\section{Ethics approval and consent to participate}

This study was approved by the Ethics Committee of Fujian Provincial Cancer Hospital (approval no. SQ2011-012-01) and signed informed consent was provided.

\section{Patient consent for publication}

Patients provided consent for the publication of the present study.

\section{Competing interests}

The authors declare that they have no competing interests.

\section{References}

1. Kumar N, Biswas S, Mathew AE, Varghese S, Mathew JE, Nandakumar K, Aranjani JM and Lobo R: Pro-apoptotic and cytotoxic effects of enriched fraction of Elytranthe parasitica (L.) Danser against HepG2 Hepatocellular carcinoma. BMC Complement Altern Med 16: 420, 2016.

2. Pan Q, Long X, Song L, Zhao D, Li X, Li D, Li M, Zhou J, Tang X, Ren H, et al: Transcriptome sequencing identified hub genes for hepatocellular carcinoma by weighted-gene co-expression analysis. Oncotarget 7: 38487-38499, 2016.

3. Fathy SA, Emam MA, Abo Agwa SH, Abu Zahra FA, Youssef FS and Sami RM: The antiproliferative effect of Origanum majorana on human hepatocarcinoma cell line: Suppression of NF- $\kappa$ B. Cell Mol Biol 62: 80-84, 2016.

4. Jayachandran A, Dhungel B and Steel JC: Epithelialto-mesenchymal plasticity of cancer stem cells: Therapeutic targets in hepatocellular carcinoma. J Hematol Oncol 9: 74, 2016.

5. Shen J, Jiang F, Yang Y, Huang G, Pu F, Liu Q, Chen L, Ju L, $\mathrm{Lu} \mathrm{M}$, Zhou F, et al: $14-3-3 \eta$ is a novel growth-promoting and angiogenic factor in hepatocellular carcinoma. J Hepatol 65: 953-962, 2016.

6. Zhang Y, Chen XM and Sun DL: Short-term outcomes of laparoscopic versus open right hemihepatectomy for hepatocellular carcinoma. Surg Laparosc Endosc Percutan Tech 26: e157-e160, 2016.

7. Cheng S, Wei $X$ and Wu M: Effective ways to improve the prognosis of advanced stage (BCLC stage C) hepatocellular carcinoma. Zhonghua Wai Ke Za Zhi 53: 324-327, 2015 (In Chinese).

8. Yang J, Jin X, Yan Y, Shao Y, Pan Y, Roberts LR, Zhang J, Huang $\mathrm{H}$ and Jiang $\mathrm{J}$ : Inhibiting histone deacetylases suppresses glucose metabolism and hepatocellular carcinoma growth by restoring FBP1 expression. Sci Rep 7: 43864, 2017.

9. Ehsani Ardakani MJ, Safaei A, Arefi Oskouie A, Haghparast H, Haghazali M, Mohaghegh Shalmani H, Peyvandi H, Naderi N and Zali MR: Evaluation of liver cirrhosis and hepatocellular carcinoma using Protein-Protein Interaction Networks. Gastroenterol Hepatol Bed Bench 9 (Suppl 1): S14-S22, 2016.

10. Menteşe A, Erkut N, Demir S, Özer Yaman S, Sümer A, Doğramacı Ş, Alver A and Sönmez M: Autoantibodies against carbonic anhydrase I and II in patients with acute myeloid leukemia. Turk J Haematol 34: 307-313, 2017.

11. Sheng WW, Dong M, Zhou JP, Kong FM and Li YJ: Clinicopathological significance of the expression of carbonic anhydrase I and II in human pancreatic cancer. Zhonghua Yi Xue Za Zhi 92: 3407-3411, 2012 (In Chinese).

12. Viikilä P, Kivelä AJ, Mustonen H, Koskensalo S, Waheed A, Sly WS, Pastorek J, Pastorekova S, Parkkila S and Haglund C: Carbonic anhydrase enzymes II, VII, IX and XII in colorectal carcinomas. World J Gastroenterol 22: 8168-8177, 2016.

13. Hu X, Huang Z, Liao Z, He C and Fang X: Low CA II expression is associated with tumor aggressiveness and poor prognosis in gastric cancer patients. Int J Clin Exp Pathol 7: 6716-6724, 2014

14. Järvinen P, Kivelä AJ, Nummela P, Lepistö A, Ristimäki A and Parkkila S: Carbonic anhydrase II: A novel biomarker for pseudomyxoma peritonei. APMIS 125: 207-212, 2017.

15. Wang Y, Jiang T, Li Z, Lu L, Zhang R, Zhang D, Wang X and Tan J: Analysis of differentially co-expressed genes based on microarray data of hepatocellular carcinoma. Neoplasma 64: 216-221, 2017.

16. Hass HG, Vogel U, Scheurlen M and Jobst J: Gene-expression analysis identifies specific patterns of dysregulated molecular pathways and genetic subgroups of human hepatocellular carcinoma. Anticancer Res 36: 5087-5095, 2016.

17. Wang J, Liu F, Ao P, Li X, Zheng H, Wu D, Zhang N, She J, Yuan J and Wu X: Correlation of PDK1 expression with clinicopathologic features and prognosis of hepatocellular carcinoma. OncoTargets Ther 9: 5597-5602, 2016.

18. Edge SB and Compton CC: The American Joint Committee on Cancer: The 7th edition of the AJCC cancer staging manual and the future of TNM. Ann Surg Oncol 17: 1471-1474, 2010. 
19. Livak KJ and Schmittgen TD: Analysis of relative gene expression data using real-time quantitative PCR and the $2^{-\Delta \Delta C_{\mathrm{T}}}$ method. Methods 25: 402-408, 2001.

20. Kai K, Koga H, Aishima S, Kawaguchi A, Yamaji K, Ide T, Ueda J and Noshiro $\mathrm{H}$ : Impact of smoking habit on surgical outcomes in non-B non- $\mathrm{C}$ patients with curative resection for hepatocellular carcinoma. World J Gastroenterol 23: 1397-1405, 2017.

21. Liang R, Lin Y, Ye JZ, Yan XX, Liu ZH, Li YQ, Luo XL and Ye HH: High expression of RBM8A predicts poor patient prognosis and promotes tumor progression in hepatocellular carcinoma. Oncol Rep 37: 2167-2176, 2017.

22. Du Z, Niu S, Xu X and Xu Q: MicroRNA31-NDRG3 regulation axes are essential for hepatocellular carcinoma survival and drug resistance. Cancer Biomark 19: 221-230, 2017.

23. Li F and Liu W: Genome-wide identification, classification, and functional analysis of the basic helix-loop-helix transcription factors in the cattle, Bos Taurus. Mamm Genome 28: 176-197, 2017.

24. Shangguan H, Tan SY and Zhang JR: Bioinformatics analysis of gene expression profiles in hepatocellular carcinoma. Eur Rev Med Pharmacol Sci 19: 2054-2061, 2015.

25. Liu M, Dou Y, Sun R, Zhang Y and Liu Y: Molecular mechanisms for alcoholic hepatitis based on analysis of gene expression profile. Hepat Mont 15: e27336, 2015.

26. Poortahmasebi V, Poorebrahim M, Najafi S, Jazayeri SM, Alavian SM, Arab SS, Ghavami S, Alavian SE, Rezaei Moghadam A and Amiri M: How hepatitis C virus leads to hepatocellular carcinoma: A network-based study. Hepat Mont 16: e36005, 2016.
27. Gokcen T, Gulcin I, Ozturk T and Goren AC: A class of sulfonamides as carbonic anhydrase I and II inhibitors. J Enzyme Inhib Med Chem 31: 180-188, 2016.

28. Fares M, Eladwy RA, Nocentini A, El Hadi SRA, Ghabbour HA, Abdel-Megeed A, Eldehna WM, Abdel-Aziz HA and Supuran CT: Synthesis of bulky-tailed sulfonamides incorporating pyrido[2,3-d][1,2,4]triazolo[4,3-a]pyrimidin-1(5H)-yl) moieties and evaluation of their carbonic anhydrases I, II, IV and IX inhibitory effects. Bioorg Med Chem 25: 2210-2217, 2017.

29. Tian MM, Fan YC, Zhao J, Gao S, Zhao ZH, Chen LY and Wang K: Hepatocellular carcinoma suppressor 1 promoter hypermethylation in serum. A diagnostic and prognostic study in hepatitis B. Clin Res Hepatol Gastroenterol 41: 171-180, 2017.

30. Leung TW, Tang AM,Zee B, Lau WY, Lai PB, Leung KL, Lau JT, Yu SC and Johnson PJ: Construction of the Chinese University Prognostic Index for hepatocellular carcinoma and comparison with the TNM staging system, the Okuda staging system, and the cancer of the liver Italian Program staging system: A study based on 926 patients. Cancer 94: 1760-1769, 2002. 